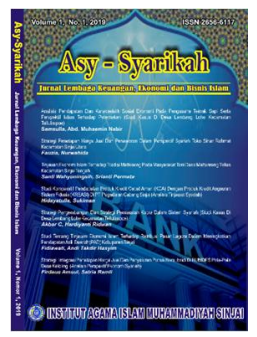

Asy-Syarikah

Jurnal Lembaga Keuangan, Ekonomi dan Bismis Islam

Volume 3, No. 1, 2021

ISSN (print) : 2656-6117

ISSN (online) : 2715-0356

Homepage : http://journal.iaimsinjai.ac.id/index.php/asy-syarikah

\title{
MANAJEMEN DANA ZAKAT SEBAGAI BANTUAN MODAL UKM UNTUK MENINGKATKAN PENDAPATAN MUSTAHIQ PADA LEMBAGA IZI CABANG SULAWESI SELATAN
}

\author{
Supriadi Muslimin ${ }^{1}$ \\ ${ }^{1}$ Sekolah Tinggi Agama Islam STAI Al-Azhar Gowa, Jl. Tamangaparaya III No.16, Makassar \\ E-mail: supriadimuslimin93@gmail.com,Tlp:+6285249402011
}

\begin{abstract}
Abstrak
Penelitian ini bertujuan untuk mengetahui pendayagunaan dana zakat dalam bidang ekonomi oleh lembaga Inisiatif Zakat Indonesia (IZI) cabang Sulawesi Selatan dan peran program pendayagunaan dana zakat dalam bidang ekonomi terhadap peningkatan kualitas ekonomi oleh lembaga Inisiatif Zakat Indonesia (IZI) cabang Sulawesi Selatan. Metode yang digunakan pada penelitian ini adalah metode kualitatif deskriptif. Jenis penelitian turun langsung ke lapangan kepada objek yang akan diteliti langsung. Penelitian lapangan atau penelitian kualitatif ini menitikberatkan pada hasil pengumpulan data dari informan yang ditentukan. Data yang dikumpulkan diolah melalui tiga tahap yaitu reduksi data, penyajian data dan penarikan simpulan. Adapun hasil dari penelitian ini menunjukkan bahwa pendayagunaan dana zakat dalam bidang ekonomi oleh lembaga Inisiatif Zakat Indonesia (IZI) cabang Sulawesi Selatan terdiri dari dua bagian yaitu lapak berkah dan latihan menjahit. Peran program pendayagunaan dana zakat dalam bidang ekonomi oleh lembaga Inisiatif Zakat Indonesia (IZI) cabang Sulawesi Selatan telah meningkatkan perekonomian mustahiq penerima bantuan modal usaha. Peningkatan perekonomian mustahiq yang mendapat bantuan modal usaha semuanya meningkat. Capaian peningkatan perekonomian mustahiq semua yang menerima bantuan modal usaha ini, menunjukkan pendayagunaan dana zakat dalam bidang ekonomi telah berperan dalam peningkatan perekonomian mustahiq oleh lembaga Inisiatif Zakat Indonesia (IZI) cabang Sulawesi Selatan
\end{abstract}

Kata Kunci: Pendayagunaan; Dana Zakat; Peningkatan Pendapatan

\section{Pendahuluan}

Masalah kemiskinan dan kesenjangan ekonomi, adalah dua hal yang harus segera diatasi guna terwujudnya tujuan pembangunan nasional seperti yang tercantum dalam Pembukaan UUD 1945 yang menegaskan bahwa salah satu tujuan negara Indonesia adalah untuk memajukan kesejahteraan umum. Penegasan tersebut tidak terlepas dari pokok pikiran yang terkandung di dalamnya, bahwa negara hendak mewujudkan keadilan sosial yang berarti pelaksanaan tercapainya kemakmuran bagi seluruh rakyat Indonesia. Pembangunan yang dilaksanakan dalam rangka pembangunan masyarakat yang seutuhnya dan pembangunan seluruh rakyat Indonesia tidak hanya mengejar kemajuan lahiriah saja, melainkan keselarasan, keserasian, dan keseimbangan antara keduanya. Begitu juga dengan pembangunan yang merata di seluruh tanah air bukan hanya untuk suatu golongan saja atau sebagian masyarakat, melainkan sebagai perbaikan tingkat hidup yang berkeadilan sosial yang menjadi tujuan dan cita-cita kemerdekaan. Berkaitan dengan hal tersebut, telah diungkapkan oleh Anies Baswedan bahwa keberhasilan suatu negara tidak 


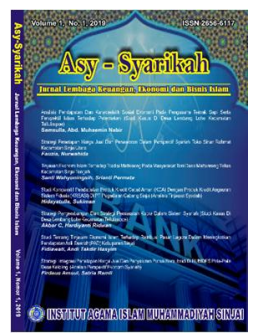

Asy-Syarikah

Jurnal Lembaga Keuangan, Ekonomi dan Bisnis Islam

Volume 3, No. 1, 2021

ISSN (print) : 2656-6117

ISSN (online) : 2715-0356

Homepage : http://journal.iaimsinjai.ac.id/index.php/asy-syarikah

diukur seberapa banyak infrastruktur yang dibangun, tapi tidak diimbangi dengan kesejahteraan masyarakat dari segi pendapatan maka belum dikatakan negara yang makmur sebagai mana esensi dari UUD 1945 yaitu kesejahteraan sosial bagi seluruh rakyat indonesia.

Zakat berpotensi besar digunakan untuk menunjang pembangunan, baik dalam aspek pengembangan peningkatan nilai-nilai moral keagamaan, juga dalam hal pemberdayaan umat pada sektor ekonomi yang kreatif dan produktif dengan menyerap banyak tenaga kerja sehingga meningkatkan kesejahteraan masyarakat atau yang lebih utama dalam hal pengembangan pendidikan. ${ }^{1}$

Lembaga Inisiatif Zakat Indonesia (IZI) cabang Sulawesi selatan telah menjalankan program pendayagunaan dana zakat untuk bantuan modal usaha dengan program lapak berkah yang langsung ditentukan berdasarkan dana zakat yang masuk, sedangkan dana infak dan sedekah diperuntukkan dalam pembinaan masyarakat. Berdasarkan hasil wawancara dengan koordinator bidang ekonomi Inisiatif Zakat Indonesia (IZI) cabang Sulawesi selatan menyatakan bahwa lembaga Inisiatif Zakat Indonesia (IZI) cabang Sulawesi selatan telah membina 30 anggota UKM di kota Makassar. ${ }^{2}$

Berdasarkan hal tersebut, pembahasan ini bertujuan untuk mengetahui pendayagunaan dana zakat sebagai bantuan modal UKM untuk meningkatkan pendapatan mustahiq yang dikelola oleh lembaga Inisiatif Zakat Indonesia (IZI) Cabang Sulawesi Selatan.

\section{Metode}

Jenis penelitian ini termasuk dalam jenis penelitian lapangan, yakni turun langsung kelapangan kepada objek yang akan diteliti. Adapun jenis penelitian yang dimaksud adalah penelitian kualitatif deskriptif. Tujuan penelitian kasus/lapangan adalah untuk mempelajari secara intensif tentang latar belakang keadaan sekarang dan interaksi lingkungan suatu unit sosial: individu, kelompok lembaga, atau masyarakat. ${ }^{3}$ Adapun lokasi yang menjadi objek penelitian penulis adalah pada lembaga Inisiataif Zakat Indonesia (IZI) cabang sulsel.

Sumber data yang digunakan dalam penelitian ini, dikelompokkan menjadi 2, yaitu:

1) Data primer adalah data yang dikumpulkan langsung dari obyeknya dan diolah sendiri oleh suatu organisasi atau perorangan. ${ }^{4}$ Maka data primer yang dimaksud merupakan data utama ${ }^{5}$ menyangkut "Manajemen Pendayagunaan Dana ZAKAT Sebagai Bantuan Modal UKM " Melalui wawancara dan observasi terhadap informan yang akan diteliti; 2) Data sekunder yaitu kepustakaan yang berkaitan dengan penelitian seperti buku, referensi, serta materi-materi tertulis yang relevan dengan tujuan penelitian. ${ }^{6}$ Data sekunder yang dimaksud yaitu sumber wawancara kemasyarakatan yang masuk dalam daftar penerima manfaat, dalam hal ini yang melakukan aktifitas pembiayaan dana ZAKAT.

${ }^{1}$ Nurul Huda, Novariani, Yosi Mardani dan Citra Permata Sari, Zakat Prspektif Mikro-Makro Pendekatan Riset, (Cet. 1; Jakarta: Kencana, 2015) h. 28

${ }^{2}$ Hasil Wawancara Pihak Koordinator Bidang Ekonomi Inisiatif Zakat Indonesia (IZI) cabang Sulawesi. 3 juli 2019

${ }^{3}$ Sumadi Suryabrata, metodologi penelitian, Ed. 2, Cet. 25, (Jakarta: Rajawali pers, 2014), h. 80

${ }^{4}$ Supranto J. Metode Ramalan Kuantitatif Untuk Perencanaab, h. 8

${ }^{5}$ Benny Kurniawan, Metodologi Penelitian (Cet. I; Tangerang: Jelajah Nusa; 2012), Edisis Pertama, h. 14.

${ }^{6}$ Benny Kurniawan, Metodologi., h. 17. 


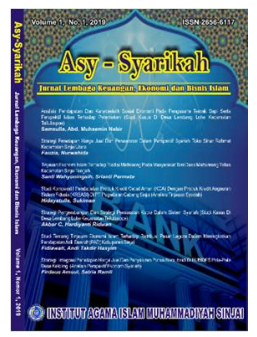

Asy-Syarikah

Jurnal Lembaga Keuangan, Ekonomi dan Bisnis Islam

Volume 3, No. 1, 2021

ISSN (print) : 2656-6117

ISSN (online) : 2715-0356

Homepage : http://journal.iaimsinjai.ac.id/index.php/asy-syarikah

Metode pengumpulan data dalam penelitia ini, yaitu: Interview (wawancara), Observasi (pengamatan/peninjauan), dan telaah dokumen.Metode dalam menganalisis data yang telah diperoleh, yaitu : 1) Reduksi data, berarti merangkum, memilih hal-hal pokok, memfokuskan pada hal-hal penting, dicari tema dan polanya dan membuang yang tidak perlu. Reduksi data ini berlangsung terus menerus selama penelitian berlangsung; ${ }^{7}$ 2) Penyajian data, dimaksudkan untuk menemukan suatu makna dari data-data yang diperoleh, kemudian disusun secara sistematis, dibentuk infomasi yang kompleks menjadi sederhana namun selektif. ${ }^{8}$ 3) Penarikan kesimpulan/verifikasi, Kesimpulan dalam penelitian kualitatif yang diharapkan adalah merupakan temuan baru yang sebelumnya belum pernah ada. Temuan dapat berupa deskripsi atau gambaran suatu obyek yang sebelumnya masih remang-remang atau gelap sehingga setelah diteliti menjadi jelas. ${ }^{9}$

\section{Hasil dan Pembahasan}

\subsection{Manajemen Dana Zakat Sebagai Bantuan Modal UKM Pada Lembaga IZI Cabang Sulsel}

Aspek manajemen merupakan bagian yang tidak terpisahkan dari beberapa aspek kajian dalam sebuah laporan kegiatan organisasi, Termasuk program dalam sebuah lembaga. Fungsi manajemen dalam terealisasi progaram ini yaitu;

Aspek manajemen merupakan bagian yang tidak terpisahkan dari beberapa aspek kajian dalam sebuah laporan kegiatan organisasi, Termasuk program dalam sebuah lembaga. Fungsi manajemen dalam terealisasi progaram ini yaitu;

\section{Planning (Perencanaan Program)}

Sebelum perencanaan terealisasi atau terlaksana sebuah program harus memiliki tolak ukur keberhasilan karena ini menjadi acuan kedepan bahawa kesuksesan betul-betul tercapai sesuai visi dan misi program.

Maka dari itu dibutuhkan manajemen strategik sebagai suatu konsep yang terkait dengan faktor waktu melibatkan suatu proses yang kontinu dan interatif dalam mencapai tujuan organisasi yang sesuai dengan kondisi lingkungan yang dihadapinya. Oleh karena itu, manajemen strategik dapat digunakan untuk mengidentifikasi kegiatan yang menjanjikan dan berfokus pada sumber daya (alam, manusia, dan buatan) untuk pengembanagan jangka panjang serta menguntungkan. ${ }^{10}$

7Sugiyono, Metode Penelitian Pendidikan Pendekatan Kuantitatif, Kualitatif, R\&D, Alfabeta, Bandung, 2013, h. 337

${ }^{8}$ Sugiyono, Metode Penelitian Pendidikan Pendekatan Kuantitatif, Kualitatif, R\&D, Alfabeta, h. 341

'Sugiyono, Metode Penelitian Pendidikan Pendekatan Kuantitatif, Kualitatif, R\&D, Alfabeta, h. 345

${ }^{10}$ Hubeis Musa Dan Najib Mukhamad, Manajemen Strategik (Dalam Pengembangan Daya Saing Organisasi), (Jakarta: Gramedia, 2014), h. 6 
Masukan

\section{Luaran}

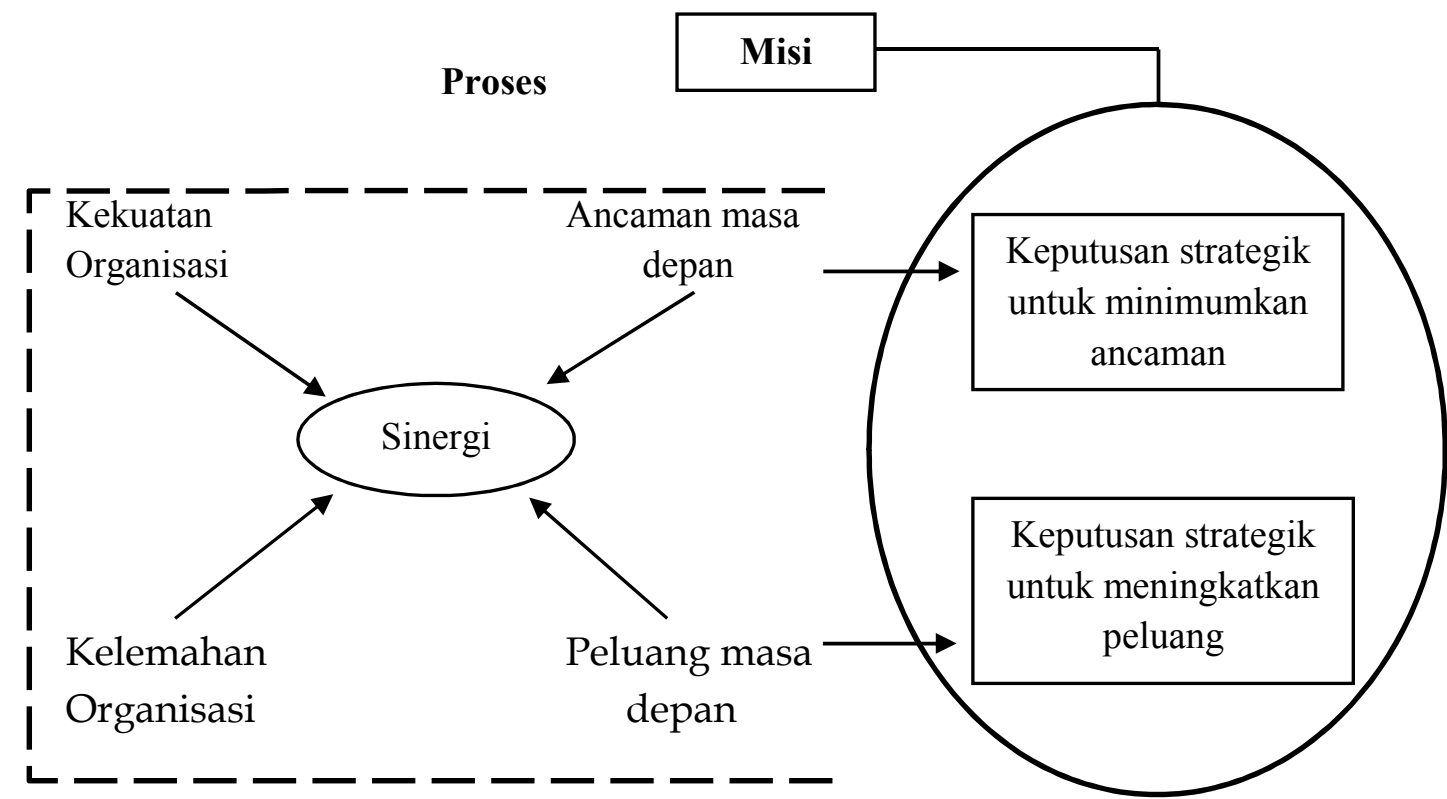

Gambar 1: Skema Penyusunan Strategi Sesuai Tahapan Masukan, Proses, Luaran.

Gambar di atas menunjukkan pentingnya para pemimpin untuk memperkirakan bahwa hari esok merupakan kelanjutan hari ini, dengan cara mengelola perubahan (lingkungan turbulen), baik sebagai peluang maupun ancaman. Penyusunan strategi erat kaitannya dengan kelompok kerja yang dibentuk dan inventarisasi kegiatan (misalanya fasilitas fisik dan sumber daya manusia, pendanaan, program, dan pengembangan) sesuai jenis kegiatan (pernah dilakukan, sedang dilakukan, dan akan dilakuakn), unit kerja yang dilibatkan (internal dan eksternal), dan status kegiatan (rutin, sosial, komersial, dan lainlain). ${ }^{11}$

Konsep strategi modern dapat dibedakan dalam kriteria sederhana (2 dimensi atau 2 $\mathrm{x}$ 2) yang berisi aspek marketing, keuangan, dan teknologi. Contoh kriteria sederhana adalah seperti yang telah dirumuskan Bostan Consulting Group yang melihat dari sisi cashflow atau sektoral (posisi produk atau pangsa/laju pasar). ${ }^{12}$

Konsep modern berorientasi pada Strengths, Weaknesses, Opportunities, dan Threats (SWOT) yang menghasilkan faktor pendorong, penghambat, dan potensi. Asumsi dasar yang melandasi adalah organisasi harus menyelaraskan aktivitas internalnya dengan realita eksternal agar dapat mencapai tujuan yang ditetapkan. Peluang tidak akan berarti manakala

11 Hubeis Musa Dan Najib Mukhamad, Manajemen Strategik (Dalam Pengembangan Daya Saing Organisasi), h. 11

12 Hubeis Musa Dan Najib Mukhamad, Manajemen Strategik (Dalam Pengembangan Daya Saing Organisasi), h. 15 


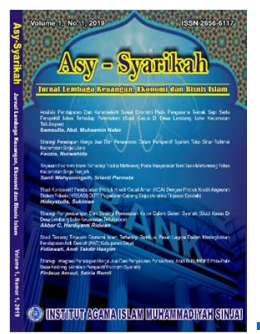

Asy-Syarikah

Jurnal Lembaga Keuangan, Ekonomi dan Bisnis Islam

Volume 3, No. 1, 2021

ISSN (print) : 2656-6117

ISSN (online) : 2715-0356

Homepage : http://journal.iaimsinjai.ac.id/index.php/asy-syarikah

perusahaan tidak mampu memanfaatkan sumber daya yang dimilikinya untuk memanfaatkan peluang tersebut.

Konsep SWOT termsuk konsep yang sederhana dan mudah dipahami sehingga relatif sangat populer khususnya dikalangan praktisi bisnis. ${ }^{13}$

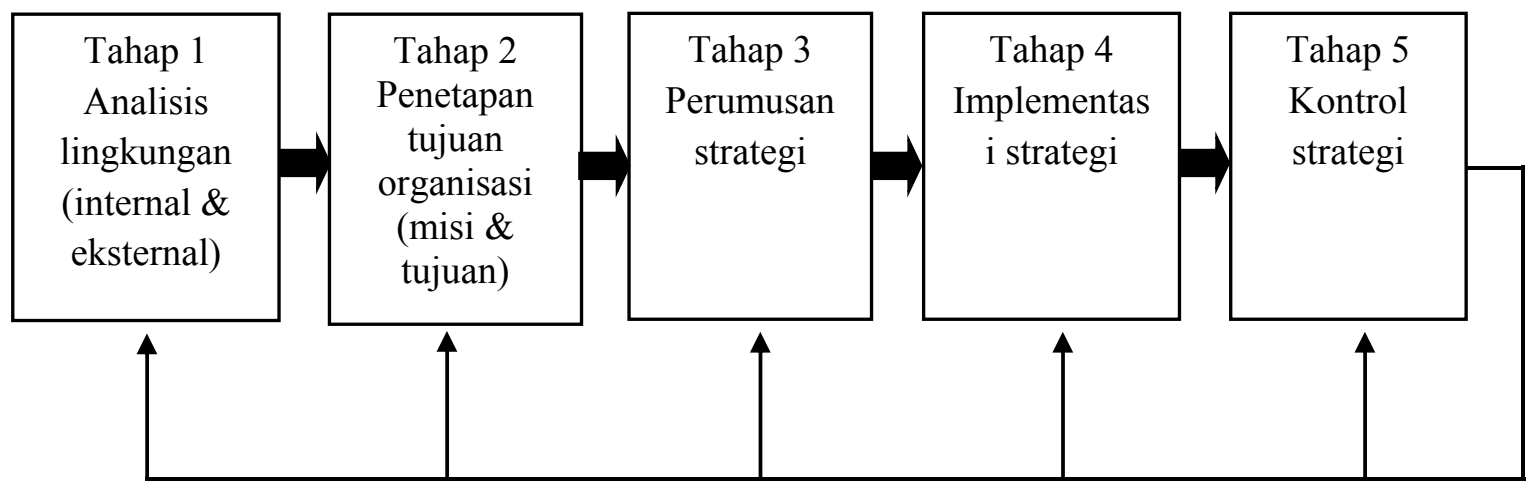

Umpan Balik

\section{Gambar 2: Tahapan Secara Umum Proses Manajemen Strategik}

Gambar 2 ialah skema proses tahapan manajemen strategik yang dirumuskan dalam lima tahapan yaitu analisis lingkungan, kemudian penetapan tujuan organisasi yang mengacu pada misi dan tujuan organisasi, lanjut perumusan strategi, dengan implementasi yaitu proses ketika rencana direalisasi, tahap terakhir adalah kontroling strategik. ${ }^{14}$

Dengan analisis SWOT ini masing-masing faktor/variabel yang berpengaruh terhadap pencapaian tujuan dianalisis plus dan minusnya (kelebihan dan kekurangannya). Dalam manajemen bisnis misalnya ada beberapa faktor yang berpengaruh yang perlu dianalisis, antara lain:
1) Segmen pasar
2) Bahan baku
3) Tenaga kerja
4) Teknologi
5) Pesaing
6) Biaya produksi
7) Lokasi

Dalam menggunakan analisis SWOT ini orang biasanya mengambil kesimpulan untuk dipilih yang terbanyak plusnya (kelebihannya) atau sedikit minusnya (kekurangannnya).

${ }^{13}$ Hubeis Musa Dan Najib Mukhamad, Manajemen Strategik (Dalam Pengembangan Daya Saing Organisasi), h. 17

${ }^{14}$ Hubeis Musa Dan Najib Mukhamad, Manajemen Strategik (Dalam Pengembangan Daya Saing Organisasi), h. 29 


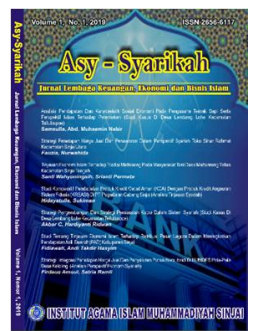

Asy-Syarikah

Jurnal Lembaga Keuangan, Ekonomi dan Bisnis Islam

Volume 3, No. 1, 2021

ISSN (print) : 2656-6117

ISSN (online) : 2715-0356

Homepage : http://journal.iaimsinjai.ac.id/index.php/asy-syarikah

\section{Organizing (Pengorganisasian)}

Pembagian pekerjaan dalam sebuah rogram menjadi hal yang sangat penting dalam mencapai tujuan yang ingin dicapai. Pembagian pekerjaan ini disertai pendelegasian kewenangan agar masing-masing melaksanakan tugasnya dengan tanggung jawab.

Struktur organisasi sangat diperlukan dalam manajemen yang mengelolah organisasi apapun. Begitu pula dalam manajemen syariah. Struktur organisasi mencerminkan pengalokasian tugas, wewenang dan tanggung jawab masing-masing orang yang ada dalam organisasi.

Secara struktural program, bagan organisasi menjadi hal yang harus dibuat untuk mengetahui susunan fungsi-fungsi, departemen-departemen, atau posisi-posisi yang menunjukkan hubungan diantaranya.

Tujuan pengorganisasian yaitu agar dalam pembagian tugas dapat dilaksanakan dengan penuh tanggung jawab dan setiap anggota organisasi dapat meningkatkan keterampilannya secara khusus dalam menjalani tugas-tugas yang di bebankan kepadanya. Adapun tujuan pengorganisasian yang lain yaitu membantu koordinasi, memperlancar pengawasan, memaksimalkan manfaat spesialisasi.

Program yang dilakukan oleh lembaga IZI cabang sulsel harusnya memiliki struktur program secara sistematik untuk memudahkan pelaksanaan tahapan-tahapan pencapaian program yang sudah direncanakan. yang memang bersarkan hasil wawancara oleh Kabid Program menyatakan bahwa saat ini tidak memiliki bagan organisasi secara terstruktur dan tertulis.

Mengapa bagan struktur organisasi harus dibuat karna untuk memudahkan tahapan pelaksanaan program dalam melakukan kontrol dan komunikasi yang masuk dalam bagian struktur pelaksanaan kegiatan. Seperti gambar 3 di bawa ini yang penulis mencoba menggambarkan bagan alur kordinasi pelaksanaan program berdasarkan keterangan Jumhar selaku Kabid Program pada saat dilakukan wawancara. 


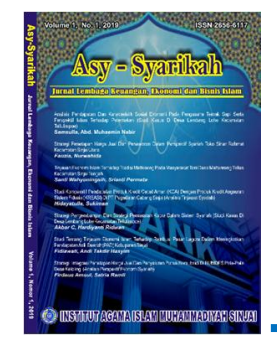

Asy-Syarikah

Jurnall Lembaga Keuangan, Ekonomi dan Bisnis Islam

Volume 3, No. 1, 2021

ISSN (print) : 2656-6117

ISSN (online) : 2715-0356

Homepage : http://journal.iaimsinjai.ac.id/index.php/asy-syarikah

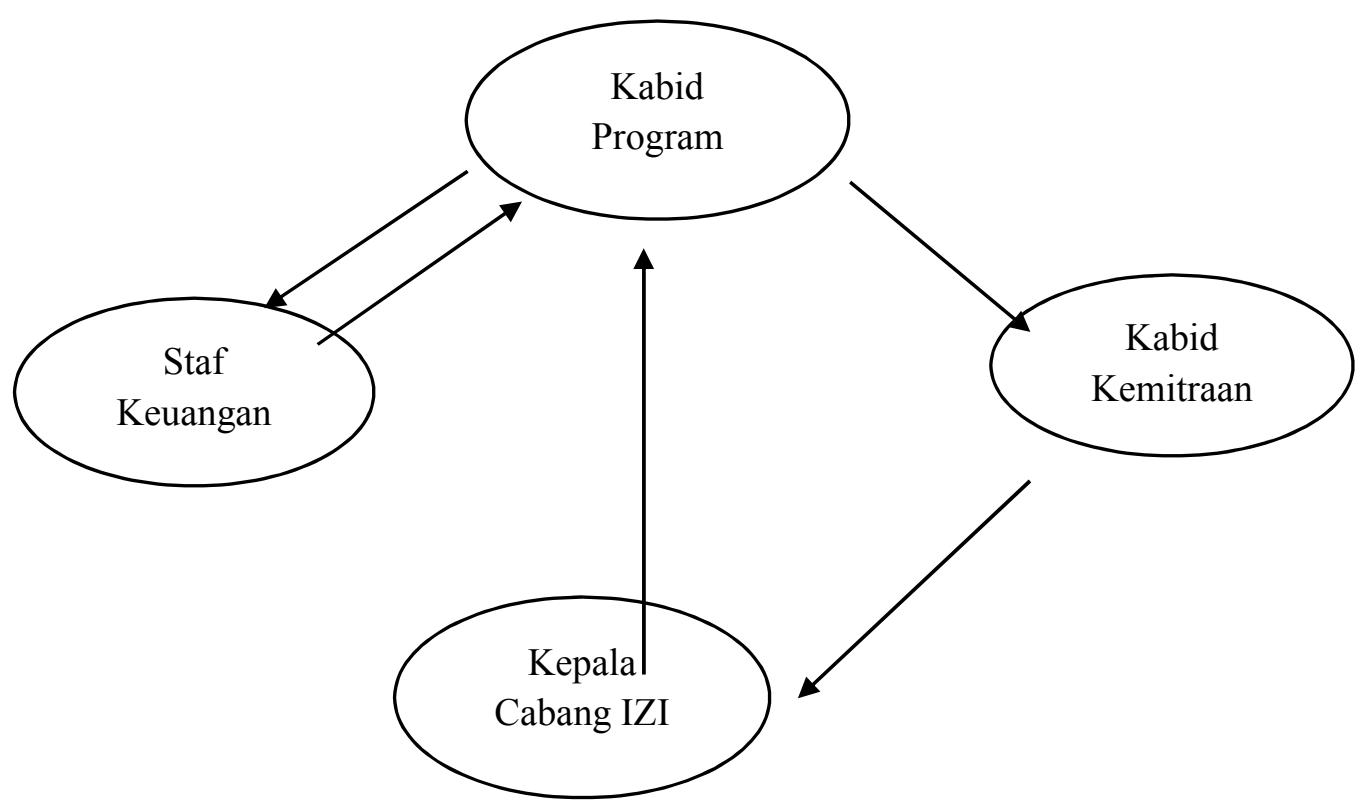

Gambar 3 : Alur Kordinasi Pelaksanaan Program

Gambar 3 ialah alur koordinasi pelaksanaan program setalah perefikasi berkas. kepala bidang program kordinsi dengan kepala bidang kemitraan setelah berkas diterima dan diperifikasi selanjutnya berkas diajukan kepada kepala cabang IZI sulsel, setelah kepala cabang mengesahkan dan menandatangani selanjutnya kepala bidang program akan diberikan surat pencairan dana dibidang keuangan untuk mencairkan dana program. 


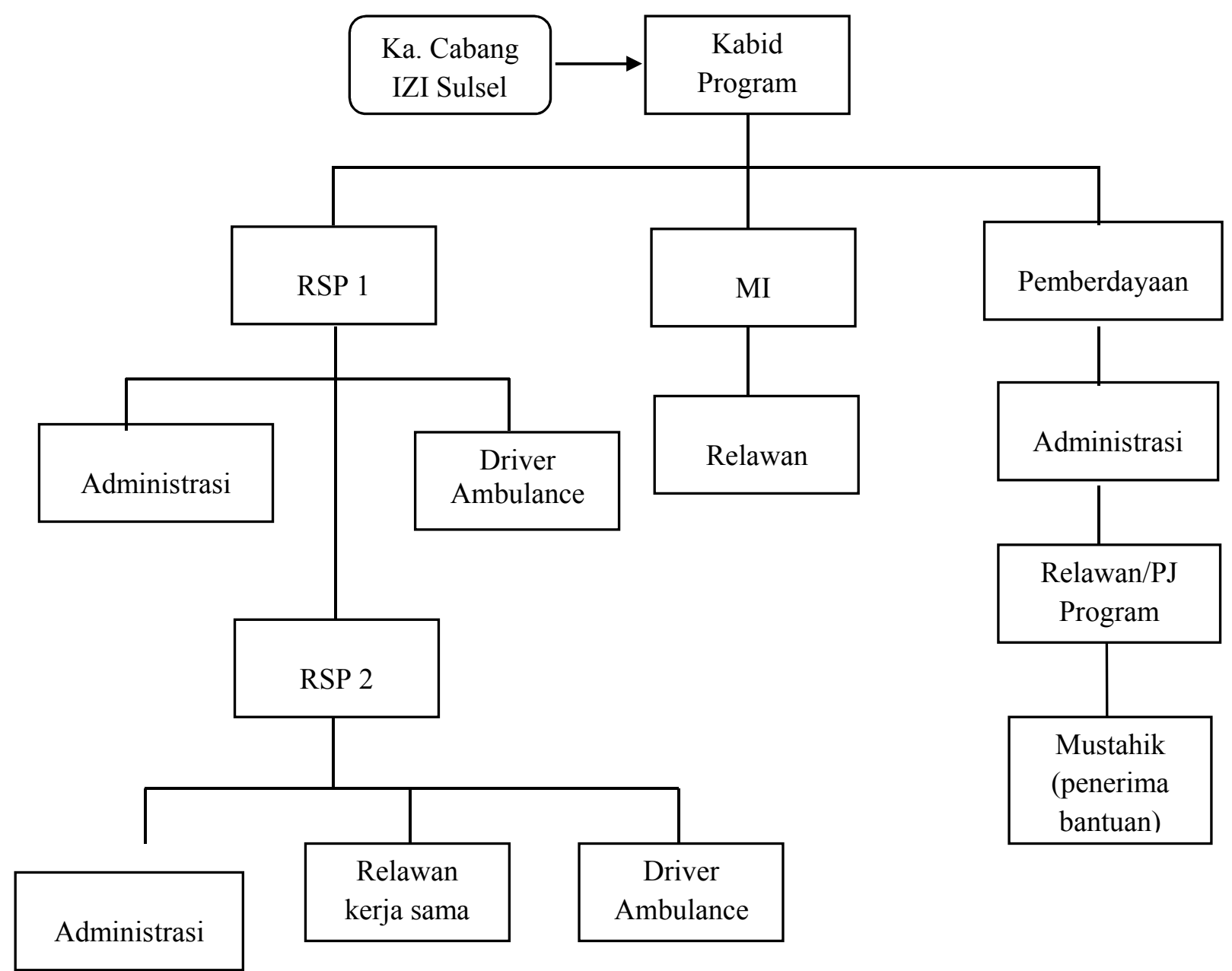

\section{Gambar 4: Struktur organisasi pelaksanaan program lembaga IZI cabang sulsel}

Gambar 4 ialah bagan struktur pelaksanaan program Inisiataif Zakat Indonesia (IZI) cabang sulsel secara umum, yang memiliki 3 program utama yaitu Rumah Singgah Pasien (RSP), Mulia Inisiatif (MI), dan Pemberdayaan. Ke tiga program ini masing-masing mempunyai alur kordinasi setiap koordinator program Kepada Kepala Bidang program.

Bisa kita lihat alaur pelaksanaan program pada gambar 3.4 diatas:

1. Rumah Singgah Pasien (RSP) yang saat ini dikoordinatori oleh Mukhlis kemudian dibantu Admin dan Driver. Adapun realisasi program ini adalah memberikan pasilitas penginapan geratis bagi pasien yang ingin berobat di rumah sakit.

2. Mulia Inisiatif (MI) yang saat ini dikoordinatori oleh Muh Ikhsan kemudian dibantu relawan yang direkrut. Adapun realisasi program ini adalah pemberian beasiswa kepada mahasiswa dan siswa.

3. Pemberdayaan yang saat ini dikoordinatori oleh Muh Fausan kemudian dibantu oleh admin dan relawan yang direkrut. Adapun realisasi program ini adalah penyaluran dana 


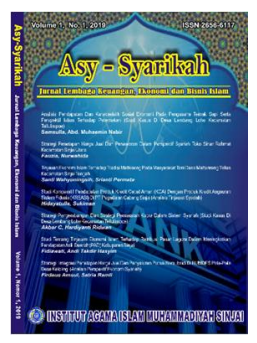

Asy-Syarikah

Jurnall Lembaga Keuangan, Ekonomi dan Bisnis Islam

Volume 3, No. 1, 2021

ISSN (print) : 2656-6117

ISSN (online) : 2715-0356

Homepage : http://journal.iaimsinjai.ac.id/index.php/asy-syarikah

zakat secara hibah dan produktif. Produktif yang dimaksud adalah pemberian bantuan modal usaha kepada mustahik yang ingin menjalankan UKM.

\section{Actuating (Pelaksaan Program)}

\begin{tabular}{|l|l|l|}
\hline \multirow{2}{*}{\multicolumn{1}{|c|}{$\begin{array}{l}\text { INISIATIF } \\
\text { ZAKAT } \\
\text { INDONESIA }\end{array}$}} & \multicolumn{2}{|c|}{ Inisiatif Zakat Indonesia } \\
\cline { 2 - 3 } & \multicolumn{2}{|c|}{ Prosedur Sistem Operasional (SOP) } \\
\cline { 2 - 3 } & Pelaksanaan Program Akademizi Dan Lapak Berkah \\
\hline No. Dokumen: & No. Revisi: & Tgl. Berlaku: \\
\hline
\end{tabular}

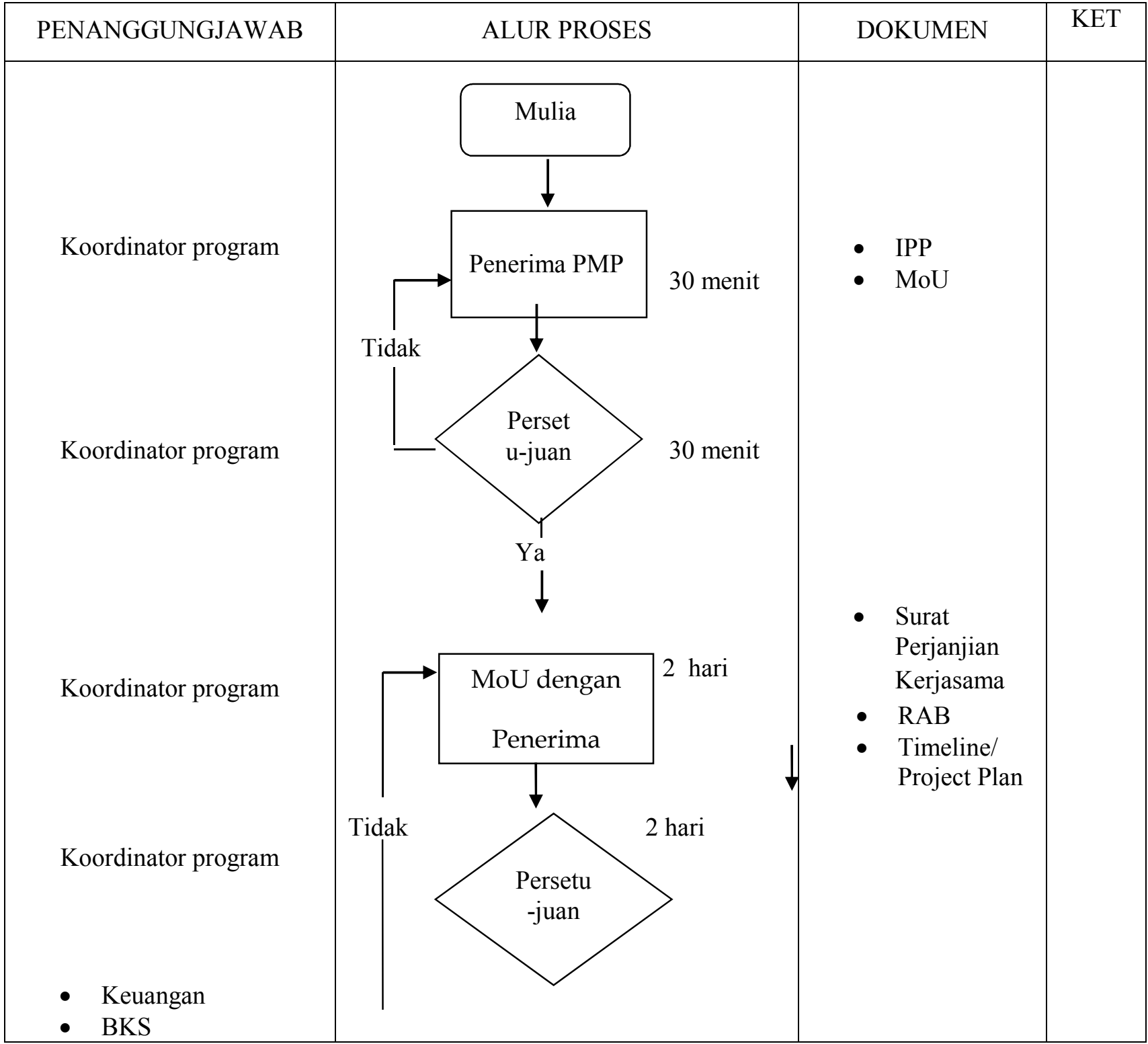


Volume 3, No. 1, 2021

ISSN (print) : 2656-6117

ISSN (online) : 2715-0356

Homepage $\quad:$ http://journal.iaimsinjai.ac.id/index.php/asy-syarikah

Koordinator program

Fasilitator

Fasilitator

Fasilitator

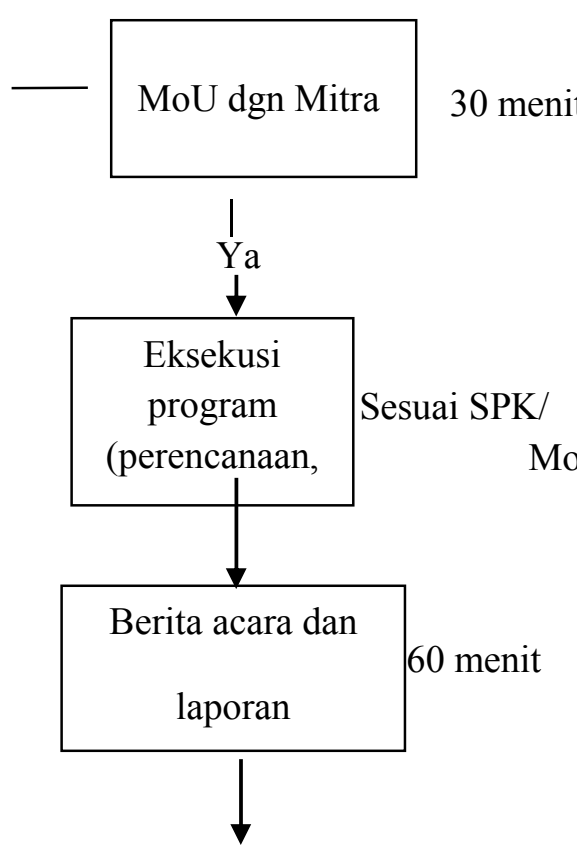

- $\mathrm{RAB}$

- Timeline/ Project

- Salinan SPK

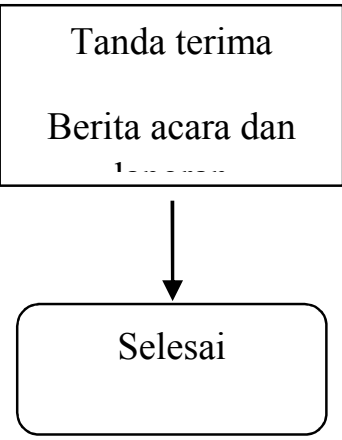

\section{Gambar 5: Prosedur Pelaksanann Program/SOP Flowchart pelaksanaan program akademizi dan lapak berkah}

Tabel 5 adalah alur proses pelaksanaan program pemberian modal usaha dan atau pemberian sarana usaha berupa gerobak atau yang sejenisnya kepada anggota usaha kecil menengah disertai dengan pendampingan singkat agar terlihat perkembangan usahanya.

Dalam pelaksanaan pemberian modal usaha dari pihak IZI sendiri sama sekali tidak memberikan persyaratan yang melibatkan pemeritah setempat, seperti harus ada persuratan-persuratan dan sebagainya. Jumhar menembahkan bahwa program ini sebelumnya sudah diabuatkan RAB tahunan ketika dananya sudah ada manajer program mengajukan permonan dana ke pada keuangan untuk dicairkan. ${ }^{15}$

15Jumhar, Kabid PDG Pendayagunaan, Kantor IZI Sulsel, Wawancara Oleh Penulis Di Makassar, 10 Juli 2019 


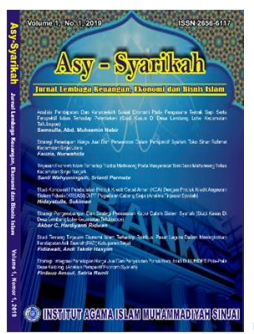

Asy-Syarikah

Jurnall Lembaga Keuangan, Ekonomi dan Bisnis Islam

Volume 3, No. 1, 2021

ISSN (print) : 2656-6117

ISSN (online) : 2715-0356

Homepage : http://journal.iaimsinjai.ac.id/index.php/asy-syarikah

4. Controling (Pengawasan program)

Pengawasan dan pengendalian dilakukan agar pelaksanaan program berjalan sesuai dengan rencana yang telah ditetapkan. Bila terjadi deviasi (penyimpangan), maka manajer segera memberikan peringatan untuk meluruskan kembali agar langkah-langkah agar sesuia dengan apa yang telah direncanakan.

Selama program berjalan dan sesuai perencanaan diawal anggota penerima bantuan modal usaha akan dilakukan pendampingan selama kurang lebih 6 bulan terhitung pada saat penyerahaan bantuan tersebut. Setelah itu manajer program atau tim akan melakukan survei lapangan yang dilakukan 1 (satu) bulan sekali untuk mengetahui apakah usaha anggota berjalan atau tidak dan apakah mengalami kendala di lapangan. ${ }^{16}$

\subsection{Program Pendayagunaan Bantuan Modal Usaha Dalam Meningkatkan Pendapatan Mustahiq Pada Lembaga Inisiatif Zakat Indonesia (IZI) Cabang Sulsel}

Program pendayagunaan dana zakat terdiri dari dua bagian, pemberian sarana dan modal usaha kepada masyarakat miskin guna menciptakan peluang usaha, serta menghadirkan solusi dalam Usaha. Sehingga para penerima manfaat memiliki kemampuan untuk dapat meningkatkan kualitas hidup mereka. Gerobak Mapan merupakan program pengembangan ekonomi mikro yang ditujukan bagi masyarakat berpenghasilan rendah yang berprofesi sebagai pedagang kecil-kecilan. Berupaya meningkatkan kepercayaan diri masyarakat dalam memulai usaha, bantuan ini bersifat langsung (charity), selain pemberian gerobak, masyarakat juga diberikan bantuan modal operasional usaha.

Pembagian atau pendayagunaan zakat sebagai bantuan modal usaha itu bersifat edukatif, produktif dan ekonomis agar para penirima zakat pada suatu masa tidak memerlukan zakat lagi, bahkan diharapkan menjadi orang yang membayar zakat. Yang berhak menrima zakat pun diperluas pemahamannya. Selain dari pengertian fakir miskin yang telah dirumuskan secara tradisional, dimasukkan pula sebagai biaya penyantunan orang-orang miskin di lembaga-lembaga sosial, panti-panti asuhan, dan bantuan modal bagi fakir miskin (mustahiq) agar mereka dapat berusaha secara produktif. ${ }^{17}$

Untuk pendayagunaan dana zakat sebagai bantuan modal usaha manjadi harapan masyarakat khususnya ketegori mustahiq. berdasarkan keterangan Hasania salah satu penerima bantuan modal usaha bahwa dengan bantuan yang dia dapatkan hasil penjualannya menjadi lebih meningkat dan produktif. Beliau juga menambahkan yang tadinya hanya mampu memenuhi kebutuhan sehari-hari namun dengan adanya bantuan modal barupa uang tunai dan gerobak bisa ngontrak rumah dan membiayai kebutuhan sekolah keponakannya yang masih duduk dibangku sekolah menengah pertama (SMP). ${ }^{18}$

Bantuan dana produktif diperuntukkan bagi mustahiq yang dikategorikan sebagai fakir miskin yang memiliki usaha kecil-kecilan. Nama penerima mengajukan permohonan

${ }^{16}$ Jumhar, Kabid PDG (Pendayagunaan), Kantor IZI Sulsel, Wawancara Oleh Penulis Di Makassar, 18 September 2019

17 Ali Muhammad Daud, Sistem Ekonomi Islam Zakat Dan Wakaf, Cet. 1, (Jakarta: UIPress 1988), h. 68

${ }^{18}$ Hasania, Mustahiq, Kec. Panakukang Kota Makassar, Sulsel, Wawancara Oleh Penulis, 23 September 2019 


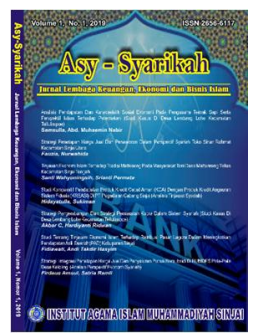

Asy-Syarikah

Jurnal Lembaga Keuangan, Ekonomi dan Bismis Islam

Volume 3, No. 1, 2021

ISSN (print) : 2656-6117

ISSN (online) : 2715-0356

Homepage : http://journal.iaimsinjai.ac.id/index.php/asy-syarikah

dan atau survey lapangan yang kemudian diseleksi oleh Inisiatif Zakat Indonesia (IZI) cabang sulsel. Dengan memperhatikan dana yang tersedia ditetapkan nama-nama mustahiq yang berhak menerima bantuan, dengan syarat:

1. Harus benar-benar dipergunakan untuk kepetingan usaha.

2. Sebelunya sudah memiliki usaha kecil-kecilan ${ }^{19}$

3. Penerima bantuan modal masyarakat kategori mustahiq

4. Mengikuti pembinaan selama waktu yang ditentukan ${ }^{20}$

Berdasarkan hasil wawancara oleh ibu Nurhayati bahwa dengan bantuan yang beliau dapatkan hasil jualannya tidak menurunkan hasil jualan sebelumnya, beliau menembahka bahwa justru dengan bantuan berupa gerobak dan uang tunai kepercayaan masyakat lebih tinggi dari segi kebersihan dan kesehatan makanannya karna berada pada naungan pembinaan IZI cabang sulsel. ${ }^{21}$

\begin{tabular}{|c|c|c|c|c|c|}
\hline No & Nama & Alamat & $\begin{array}{c}\text { Penghasilan } \\
\text { (Rp) }\end{array}$ & $\begin{array}{l}\text { Keterangan/ } \\
\text { Kebutuhan }\end{array}$ & $\begin{array}{c}\text { Jenis } \\
\text { Bantuan } \\
\end{array}$ \\
\hline 1 & $\begin{array}{l}\text { Petty Cendy } \\
\text { Tuapattinaya }\end{array}$ & $\begin{array}{l}\text { Jl. Terong } \\
\text { No. } 15\end{array}$ & $\begin{array}{l}300,000- \\
400,000 / \text { Hari }\end{array}$ & $\begin{array}{l}\text { Jualannaya Lancar } 2 \\
\text { Tahun/Gerobak }\end{array}$ & $\begin{array}{l}\text { Gerobak } \\
+ \text { Modal }\end{array}$ \\
\hline 2 & Rana Dg. Suji & $\begin{array}{l}\text { Jl. Swadaya } \\
\text { No.4 }\end{array}$ & 40,000/Hari & $\begin{array}{l}\text { Etalase Kue dan Modal } \\
\text { Usaha }\end{array}$ & $\begin{array}{l}\text { Etalase+ } \\
\text { Modal }\end{array}$ \\
\hline 3 & Yuliani & $\begin{array}{l}\text { Jl. Petta } \\
\text { Ponggawa } \\
\text { Lr. } 5 \text { No } 20\end{array}$ & $150,000 /$ Hari & $\begin{array}{l}\text { Jualannya Lancar } 1 \\
\text { Tahun/Gerobak }\end{array}$ & $\begin{array}{l}\text { Gerobak } \\
\text { + Modal }\end{array}$ \\
\hline 4 & Salma & $\begin{array}{l}\text { Jl. Naja Dg. } \\
\text { Nai No. } 51\end{array}$ & $\begin{array}{l}50,000- \\
100,000 / \text { Hari }\end{array}$ & $\begin{array}{l}\text { Jualannya } 8 \\
\text { Bulan/Gerobak }\end{array}$ & $\begin{array}{l}\text { Gerobak } \\
+ \text { Modal }\end{array}$ \\
\hline 5 & Subaeda & $\begin{array}{l}\text { J1. Swadaya } \\
6 \text { Cambaya }\end{array}$ & $\begin{array}{l}\text { 100,000- } \\
300,000 / \text { Hari }\end{array}$ & $\begin{array}{l}\text { Jualannya Lancar } 10 \\
\text { Tahun/Gerobak dan } \\
\text { Modal }\end{array}$ & $\begin{array}{l}\text { Gerobak } \\
+ \text { Modal }\end{array}$ \\
\hline 6 & Risnawati & $\begin{array}{l}\text { Bujjulu, } \\
\text { Lingkungan } \\
\text { Ujungbola }\end{array}$ & $\begin{array}{l}300,000- \\
500,000 / \text { Hari }\end{array}$ & $\begin{array}{l}\text { Jualannya Lancar } 3 \\
\text { Tahun/ Gerobak dan } \\
\text { Modal }\end{array}$ & $\begin{array}{l}\text { Gerobak } \\
+ \text { Modal }\end{array}$ \\
\hline 7 & Arwini Puspita & Mariso & $\begin{array}{l}20,000- \\
100,000 / \text { Hari }\end{array}$ & Modal & Modal \\
\hline 8 & Taufiq Hidayat & $\begin{array}{l}\text { Jl. Sungai } \\
\text { Saddang } \\
\text { Baru Lr. } \\
\text { Mu'minim } \\
\text { No.8 }\end{array}$ & $\begin{array}{l}\text { Gerobak dan } \\
\text { Modal }\end{array}$ & $\begin{array}{l}\text { MIE Pedas/Kedai fii } \\
\text { Hifzillah }\end{array}$ & $\begin{array}{l}\text { Gerobak } \\
+ \text { Modal }\end{array}$ \\
\hline
\end{tabular}

\footnotetext{
${ }^{19}$ Ali Muhammad Daud, Sistem Ekonomi Islam Zakat Dan Wakaf, h. 70

${ }^{20}$ IZI Cabang Sulsel, Term Of Reference, Program Lapak Berkah, Makassar, 2019

${ }^{21}$ Nurhayati, Mustahiq, Kec. Panakukang Kota Makassar, Sulsel, Wawancara Oleh Penulis, 23 September 2019
} 


\begin{tabular}{|c|c|c|c|c|c|c|}
\hline \multicolumn{2}{|c|}{ 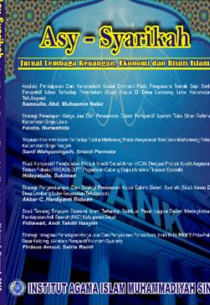 } & \multicolumn{5}{|c|}{$\begin{array}{l}\text { Asy-Syarikah } \\
\text { Jurnal Lembaga Keuangan, Ekonomi dan Bisnis Islam } \\
\text { Volume 3, No. 1, 2021 } \\
\text { ISSN (print) : 2656-6117 } \\
\text { ISSN (online) : } 2715-0356 \\
\text { Homepage : http://journal.iaimsinjai.ac.id/index.php/asy-syarikah }\end{array}$} \\
\hline 9 & & $\begin{array}{l}\text { Ahmad } \\
\text { amsi }\end{array}$ & \begin{tabular}{|l} 
Perumahan \\
Zarindah \\
Permai Blok \\
D/3
\end{tabular} & Tidak Menentu & Gerobak dan Modal & $\begin{array}{l}\text { Gerobak } \\
\text { + Modal }\end{array}$ \\
\hline 10 & & Andriani & $\begin{array}{l}\text { J1. Maros } 7 \\
\text { Blok B No. } \\
124\end{array}$ & & $\begin{array}{l}\text { Tidak Berada Ditempat } \\
\text { disaat Survey }\end{array}$ & $\begin{array}{l}\text { Gerobak } \\
+ \text { Modal }\end{array}$ \\
\hline 11 & & waty & $\begin{array}{l}\text { Jl. Toddouli } \\
18 \text { No. } 55\end{array}$ & Tidak Menentu & Modal & Modal \\
\hline 12 & & inus & $\begin{array}{l}\text { Jl. Borong } \\
\text { Jambu } \\
\text { Belakang }\end{array}$ & & Gerobak dan Modal & $\begin{array}{l}\text { Gerobak } \\
+ \text { Modal }\end{array}$ \\
\hline 13 & & anti & $\begin{array}{l}\text { Toddopuli } 7 \\
\text { STP } 3\end{array}$ & & $\begin{array}{l}\text { Modal Untuk } \\
\text { Merenovasi Tempat } \\
\text { Jualannya }\end{array}$ & $\begin{array}{l}\text { Renov } \\
\text { Tempat } \\
\text { Jualan }+ \\
\text { Modal }\end{array}$ \\
\hline 14 & & ardani Azakat & $\begin{array}{l}\text { Jl. Andi } \\
\text { Mangerangi } \\
\text { Lr } 7 \text { B No. } \\
11\end{array}$ & $\begin{array}{l}40,000- \\
400,000 / \text { Hari }\end{array}$ & $\begin{array}{l}\text { Jualannya lancar } 2 \\
\text { Tahun/Kendaraan } \\
\text { (Motor Bekas) }\end{array}$ & $\begin{array}{l}\text { Motor } \\
\text { Bekas }+ \\
\text { Modal }\end{array}$ \\
\hline 15 & & & $\begin{array}{l}\text { Jl. Andi } \\
\text { Mangerangi } \\
\text { I Lr. } 2 / 17\end{array}$ & $400,000 /$ pekan & $\begin{array}{l}\text { Jualannya Lancar } 30 \\
\text { Tahun/Etalase dan } \\
\text { Modal }\end{array}$ & $\begin{array}{l}\text { Gerobak } \\
\text { + Modal }\end{array}$ \\
\hline
\end{tabular}

Tabel 1: Hasil Survey Lapak Berkah di sekitar kota Makassar Yang sudah berjalan di tahun 2018

\begin{tabular}{|c|c|c|c|}
\hline \multirow[b]{2}{*}{ Nama } & \multicolumn{2}{|c|}{ Astimasi Pendapatan } & \multirow[b]{2}{*}{ Jenis Bantuar } \\
\hline & $\begin{array}{c}\text { Sebelum } \\
\text { Dapat Bantuan }\end{array}$ & $\begin{array}{c}\text { Setelah } \\
\text { Dapat bantuan }\end{array}$ & \\
\hline Petty Cendy Tuapattinaya & Rp300.000/hari & Rp400.000/Hari & $\begin{array}{l}\text { Gerobak + } \\
\text { Modal }\end{array}$ \\
\hline Rana Dg. Suji & Rp60.000/hari & Rp100.000/Hari & $\begin{array}{l}\text { Etalase+ } \\
\text { Modal }\end{array}$ \\
\hline Yuliani & Rp75.000/hari & Rp150.000/Hari & $\begin{array}{l}\text { Gerobak + } \\
\text { Modal }\end{array}$ \\
\hline Salma & Rp70.000/hari & Rp100.000/Hari & $\begin{array}{l}\text { Gerobak + } \\
\text { Modal }\end{array}$ \\
\hline Subaeda & Rp200.000/hari & Rp300.000/Hari & $\begin{array}{l}\text { Gerobak + } \\
\text { Modal }\end{array}$ \\
\hline
\end{tabular}




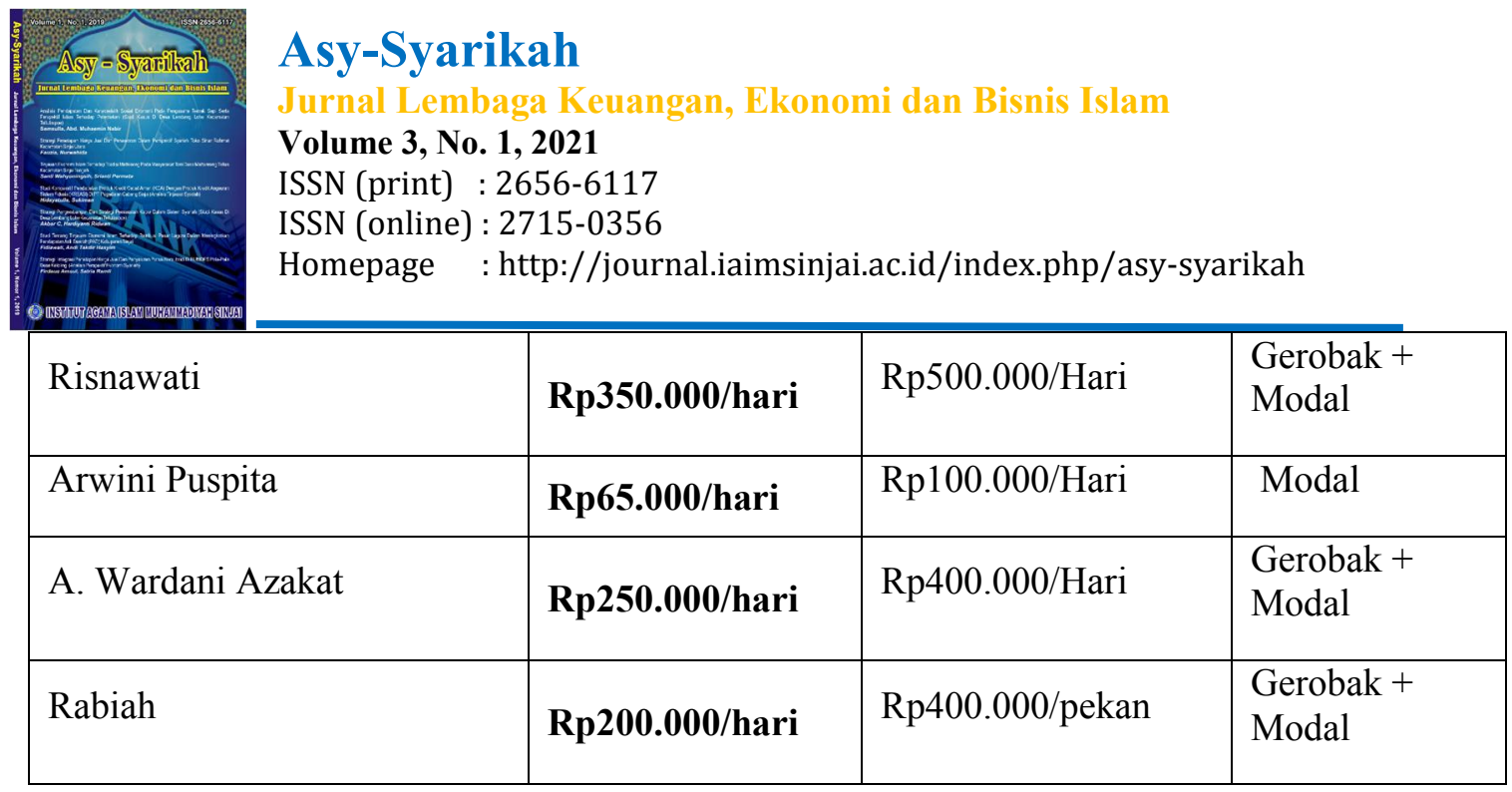

Tabel 2 : Astimasi pendapatan sebagian mustahik penerima bantuan modal usahaYang sudah berjalan tahun sampai sekarang

Tabel tersebut menunjukan bahwa tingkat pendapatan masyarakat dalam menjalankan usaha kecil menengah sangat produktif dalam membekap kebutuhan ekonomi masyarakat dalam memenuhi kebutuhan sehari-hari. bisa dilihat dari hasil survey ini rata-rata pendapatan masyarakat yang menjalankan usaha ini mereka bisa menghasilkan Rp.100-300 ribu/hari dalam sebulan bisa mencapai Rp. 3.000.000,- - Rp. 9.000.000. jika ini yang dikembangkan maka kemiskinan yang ekonominaya menengah kebawa akan teratasi, Apa lagi saat ini masyarakat khususnya yang berprofesi sebagai pegawai negeri maupun swasta itu lebih senang membeli makanan yang sudah jadi, berhubung karna kesibukan yang mereka jalani sehingga memilih untuk memesan dan membeli makanan yang suadah siap saji dari pada memasak sendiri untuk sarapan pagi, makanan siang dan makan malam.

Kondisi ini tentu menjadi peluang yang besar bagi anggota usaha kecil dan menangah untuk kelancaran dan keuntungan dagangannya, dan ini juga menjadi tantangan bagi pelaku usaha kecil menengah bagaimana kemudian inofasi dan kreatifitas pelaku usaha bahwa dagangan mereka itu disukai dan diminati banyak orang, sehingga dangangan mereka bisa habis terjual setiap hari sehingga perputaran modal lancar dan keuntungan semakin besar.

Dengan adanya program lapak berkah dari lembaga IZI sulsel sangat membantu dan mendorong kemajuan usaha masyarakat untuk lebih produktif karna tidak bisa dipungkiri bahwa bantuan berupa barang atau jasa sangat diperlukan untuk peningkatan pelaku usaha kecil menengah.

Namun dalam proses pemberian bantuan ini tetap dalam tahap rekrutment atau pembatasan, berhubung karna bantuan ini bersumber dari dana zakat yang memiliki aturan dalam pengalokasiannya. pembatasan yang dimaksud adalah pihak IZI sulsel lebih focus pada mustahiq yang sebelumnya sudah mempunyai usaha kecil-kecilan yang sudah berjalan. kondisi kemudian barulah diberikan bantuan tambahan modal untuk peningkatan dagangannya.

Berdasarkan data-data hasil penelitian, pembahasan hasil penelitian dapat diuraikan dalam dua pembahasan yaitu tentang manajemen dana zakat sebagai bantuan modal Usaha Kecil Menengah (UKM) pada lembaga Inisiatif Zakat Indonesia (IZI) cabang Sulawesi Selatan dan pendayagunaan bantuan modal usaha dalam meningkatkan pendapatan mustahik pada lembaga Inisiatif Zakat Indonesia (IZI) cabang Sulawesi Selatan. 


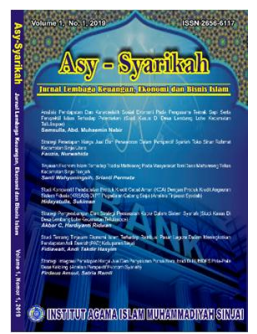

Asy-Syarikah

Jurnal Lembaga Keuangan, Ekonomi dan Bisnis Islam

Volume 3, No. 1, 2021

ISSN (print) : 2656-6117

ISSN (online) : 2715-0356

Homepage : http://journal.iaimsinjai.ac.id/index.php/asy-syarikah

Pertama, tentang manajemen dana zakat sebagai bantuan modal Usaha Kecil Menengah (UKM) pada lembaga Inisiatif Zakat Indonesia (IZI) cabang Sulawesi Selatan tentu tidak lepas dari aspek dan tahapan-tahapan manajemen sebagai tolak ukur keberhasilan program yang ingin dicapai dalam sebuah organisasi atau lembaga.

Aspek manajemen merupakan bagian yang tidak terpisahakan dari beberapa aspek kajian dalam sebuah laporan kegiatan organisasi. Keberhasilan dalam sebuah program yang akan dilaksanakan sangat dipengaruhi oleh peran manajemen dalam mencapai keberhasilan. Aspek manajemen dalam hal ini menyangkut fungsi-fungsi manajemen secara umum untuk menjadikan tolak ukur keberhasil program lapak berkah yang dilakukan oleh lembaga IZI cabang sulsel.

Inisiatif Zakat Indonesia cabang sulsel sebagai lembaga yang besar harus memiliki tahapan-tahapan perencanaan yang tertruktur agar pelaksanaan progran yang dijalankan bisa berjalan dengan efektif. Dengan tahapan ini akan memudahkan mengukur asumsi dasar aktivitas internal dalam realita eksternal agar dapat mencapai tujuan yang ingin dicapai. Untuk itu konsep SWOT harus diperhatikan untuk melihat kekuatan, kelemahan, peluang, dan ancaman dalam menjalankan sebuah program.

Saat ini secara terstruktur tahapan-tahapan ini tidak terorganisasi dalam bentuk bagan yang dilakukan oleh lembaga IZI cabang sulsel yang dituangkan dalam bentuk tulisan untuk dijadikan panduan dan data base lembaga, sehingga selama menjalan program lapak berkah tidak memiliki titik tolak ukur pencapaian keberhasilan, hanya melihat jalan tidaknya usaha yang dibina jika masih berjalan jualannya itu dianggap program ini berjalan baik. Padahal tolak ukur keberhasilan tidak hanya dilihat dari jalan tidaknya sebuah usah yang dijalankan namun pengaru internal dan ekstarnal juga menjadi aspek utama yang harus diketahui. Untuk itu fungsi manajemen seperti perencaan, pengorganisasian, pelaksanaan, dan pengawasan harus terealisasi dalam menjalankan sebuah program.

Kedua tentang program pendayagunaan bantuan modal usaha dalam meningkatkan pendapatan mustahik pada lembaga Inisiatif Zakat Indonesia (IZI) cabang Sulawesi Selatan memberikan dua jenis bantuan berupa uang tunai dan berupa sarana jualan.

Dari dua jenis bantuan ini ceara penyelurannya dibagi dalam dua bentuk ada yang diberikan bantuan hanya berupa uang tunai saja ada juga yang diberikan berupa barang seperti gerobak ples uang tunai. Dalam pelaksanaan pemberian bantuan ini pihak IZI tidak memberikan persyaratan yang melibatkan pemerintah setempat, seperti harus ada persuratan-persuratan dan sebagainya. Kabid program menambahkan bahwa program ini sudah dibuatkan RAB tahunan ketika dananya sudah ada manajer program mengajukan permohonan dana kepada keuangan untuk dicairkan.

Harapan kedepannya dari pihak lembaga Inisiatif Zakat Indonesia (IZI) cabang sulsel bagi penerima bantuan modal usaha ini natinya tidak tergolong mustahik lagi justru dihapkan menjadi orang muzakki (mengeluarkan zakat).

\section{Simpulan}

Dalam persfektif hukum Islam zakat menjadi hal yang sangat penting dalam membangun pendapatan ummat Islam. Pemberian modal usaha kepada anggota UKM dengan menggunakan dana zakat dalam program lapak berkah yang dilakukan lembaga 


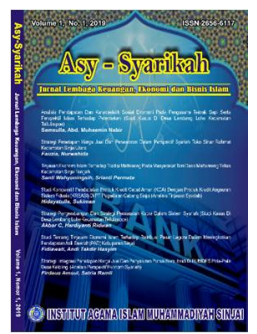

Asy-Syarikah

Jurnall Lembaga Keuangan, Ekonomi dan Bisnis Islam

Volume 3, No. 1, 2021

ISSN (print) : 2656-6117

ISSN (online) : 2715-0356

Homepage : http://journal.iaimsinjai.ac.id/index.php/asy-syarikah

Inisiatif Zakat Indonesia (IZI) cabang sulsel menjadi harapan masyarakat khususnya kategori mustahiq yang ingin membangun usaha kecil menengah.

Dengan adanya program lapak berkah yang dilakukan oleh lembaga Inisiatif Zakat Indonesia (IZI) cabang sulsel yaitu dengan memberikan bantuan modal usaha kepada masyarakat yang tergolong mustahiq fakir miskin maka diharapkan yang mendapat kesempatan mendapatkan bantuan modal usaha bisa produktif dan berharap kedepannya yang tadinya sebagai penerima zakat mustahiq berubah menjadi muzakki yang mengeluarkan zakat, sesuai hakikat dari zakat itu sendiri adalah tumbuh.

\section{Daftar Pustaka}

Ali Daud, Muhammad (1998). Sistem Ekonomi Islam Zakat Dan Wakaf. Jakarta:UI-Press. Hasania, Mustahiq, Kec. Panakukang Kota Makassar, Sulsel, Wawancara Oleh Penulis, 23 September 2019

Hasil Wawancara Pihak Koordinator Bidang Ekonomi Inisiatif Zakat Indonesia (IZI) cabang Sulawesi. 3 juli 2019

Hubeis Musa dan Najib Mukhamad (2014). Manajemen Strategik (Dalam Pengembangan Daya Saing Organisasi), Jakarta:Gramedia.

IZI Cabang Sulsel, Term Of Reference Program Lapak Berkah, Makassar, 04 januari 2019 Jumhar, Kabid PDG (Pendayagunaan), Kantor IZI Sul-Sel, wawancara oleh penulis di Makassar, 10 Juli 2019

Kurniawan, Benny. Metodologi Penelitian (2012), Cet. I; Tangerang: Jelajah Nusa; Edisis Pertama

Nurhayati, Mustahiq, Kec. Panakukang Kota Makassar, Sulsel, Wawancara Oleh Penulis, 23 September 2019

Nurul Huda, Novariani, Yosi Mardani dan Citra Permata Sari (2015), Zakat Prspektif Mikro-Makro Pendekatan Riset, Jakarta: Kencana.

Sugiyono, Metode Penelitian Pendidikan Pendekatan Kuantitatif Kualitatif, R\&D (2013). Bandung: Alfabeta

Supranto J, Metode Ramalan Kuantitatif Untuk Perencanaab (2000). Cet. 2, Jakarta: PT Rineka Cipta 2000.

Suryabrata, Sumadi. Metodologi Penelitian (2014). Ed. 2, Cet. 25, Jakarta: Rajawali Pers. 